\title{
Proactive Means for Engineering Students' Edification on Sustainability
}

\section{Dr. Saed Talib Amer, Khalifa University}

Dr. Saed Amer is an assistant professor at Khalifa University of Science and Technology. His research focuses on computer integrated manufacturing and robot controlled nondestructive testing.

Dr. Amer also worked on sustainability Metrics Research and systematic measures to enforce engineering sustainability education. Previous work included seat comfort analyses for Boeing aircrafts and robotics solutions for Unexploded Ordnance (UXO) remediation. Finally, Dr. Amer worked on simulation solutions for hybrid renewable energy research.

Dr. Amer earned his Doctorate of Philosophy in Computer and Information Systems Engineering in August, 2012 from Tennessee State University, USA.

\section{Dr. Jaby Mohammed, Khalifa University of Science and Technology}

Jaby Mohammed is a faculty at The Khalifa University, Abu Dhabi, UAE. He received his PhD in Industrial Engineering from University of Louisville (2006), masters in Industrial Engineering from University of Louisville (2003) and also a master's in business administration from Indira Gandhi National Open University (2001). His research interests include advanced manufacturing, design methodologies, six sigma, lean manufacturing, and engineering education. He previously taught at Indiana Purdue Fort Wayne, IN and at Morehead State University, KY. He is a member of IIE, SME, ASQ, ASEE, and Informs.

\section{Dr. Ali Bouabid, Khalifa University of Science and Technology}

Dr. Ali Bouabid is currently assistant professor in the Industrial and Systems Engineering department at Khalifa University of Science and Technology in Abu Dhabi, UAE. Prior to that, he held a faculty position in the General Studies department at the Petroleum Institute, in Abu Dhabi, UAE, where he taught and was coordinator of freshmen engineering courses (ENGR101 and ENGR110). He also taught Engineering Design courses (STPS201 and STPS251) and Mechanical Engineering course (MEEGG201). Prior to these appointments in the UAE, Dr. Bouabid was associate professor and Engineering Program coordinator at Piedmont Virginia Community College (PVCC) from 2006 to 2014, where he contributed to develop the Engineering program and to establish transfer agreements between PVCC and several universities in Virginia, such as UVA, VT, ODU, and GMU. His research interests are mainly on Engineering Education and on Environmental Systems. He has contributed to the development of a decision support system for sustainable access to water supply and sanitation services in developing countries. His current research includes investigating potential pathways to transitioning from fossil fuels to renewable energy solutions in developing countries. Prior to his academic career, Dr. Bouabid worked in the industry (engineering and manufacturing) for more than 12 years in France and in Morocco, where he held several management positions. Dr. Bouabid holds a DEST (BS) and an Engineer degree (MSc) in Mechanical Engineering from the Conservatoire National des Arts et Métiers of Paris, France and a MSc and a PhD degree in Systems Engineering from the University of Virginia, USA. 


\title{
Proactive Means for Engineering Students' Edification on Sustainability
}

\begin{abstract}
A vigorous role of engineers is to uphold and advocate sustainability, yet, this role is often overlooked especially in regions where the guidelines of sustainability are enforced but not trusted. The problem seems to resonate on the motives not the practice, hence, it is very important to quantify sustainability and show measurable merits that encourage professionals to adhere to sustainability. Textbook pedagogy succeeds in explaining the procedure but failed to provoke the student's interest, therefore, a new methodology is needed to teach sustainability to freshmen engineering students by means of interactive and collaborative approaches. The core goal of this work is to engage the students' skills and enhance their social, environmental and economic confidence to generate solutions that are both sustainable and humane. One of the objectives is to expose the students to engineering tools such as CAD, MATLAB, NN and other cutting-edge tools. Also, it is important to enhance the student's research skills and improve their communication skills such as report writing and presentations. The proposed study suggests employing computer aided engineering and multi-paradigm numerical computing tools that provide suitable means to generate multiple scenarios with diverse parameters then propose and test possible solutions. Such tools allow for CAD simulations of multiple product that impose high impacts when recycled and are also perceived as high demand items. The tools also provide data structures, probability analyses and graphical presentations of the findings. The students then probe different theories which enhance sustainable practices that reduce resources exploitations then propose solutions that can be modeled and tested.
\end{abstract}

\section{Introduction}

Sustainability is defined with different terms within different scopes which confirms its importance to many professions. For example, sustainability in the economical scope can be defined as the ability to maintain and increase the national Gross Domestic Products (GDP) or the total amount of annual production produced within the borders of the country [1]. In another scope, sustainability is the maintenance of the community social structure and services that meet the needs of the current communities and guide the future generation to uphold healthy social values [2]. However, it takes faith in sustainability to build the pillars to save resources for now and later. In other words, it is one noble practice that reflects on the society's civility and security. While it is easy to persuade people to follow the sustainability rules through guidelines and laws, it is hard to have them believe it is the right thing to do. Some blame such fallacy on the slow tangible consequences; i.e. if one cannot see and feel the consequences fast, all efforts are seen as waste of time [3]. Another reason to blame is the lack of clear and robust metrics to properly measure and track sustainability which, in turn, reduces the adherence and motivation [4]. Other scholars blame the authorities for inadequate incentives to those who undertake sustainability initiatives [5]. Furthermore, following poor sustainability models lead many companies to report losses which drove people away from such initiative [6]. 
Unfortunately, these challenges do not stop at the industry; education on sustainability is also affected with such challenges. For instance, in many situations, sustainability education is ignored or barely addressed and the developing awareness within the educational community and the public is often neglected causing hindrance on sustainability acceptance [7]. The lack of orienting the entire education system to effectively adapt sustainability is another shortcoming in engineering education which weakens the sustainable development and makes it difficult to teach due to knowledge gaps. Another challenge is the failure to connect the students' learning with the existing controversial sustainability issues. Students are still taught to focus on recycling as the main exercise of sustainability; yet, many issues that our students face in their everyday walk of life are not connected to their correct sustainable measures [8].

This work proposes multiple systematic approaches that helps to enhance the education and trust in sustainability. The first approach recommended in this work is research which keeps the students involved and absorbed in the people's distress here and now. This research will be a dynamic tool that keeps running to achieve a successful solution. The second component is a Computer Aided Engineering (CAE) capability; CAE provide the students with efficient outcomes while opening the possibilities for multiple scenarios. Many advantages are recognized for computer modeling over physical prototyping such as convenience of workplace which is not limited by laboratories or equipment. Another advantage is the freedom of time which is available whenever a computer is available. In addition, the time to achieve the task is always reduced when working with computers [9]. Moreover, one of the predominant advantages of computer modeling is allowing for fast modification swiftly and economically. This fast and easy manipulation of the parameters is very helpful to show the students how little compromises in one's lifestyle may lead to significant sustainable merits. Finally, research is assigned to the students aiming to ensure feasible modeling and exposing the importance of sustainability on homes and families. Computer aided engineering is a branch of CAD responsible for engineering analyses and simulation. CAD software are diverse, plentiful and pursuing to provide accurate and expedited results, however, such programs are black-boxed, i.e. the users are not concerned with the data crunching processes that deliver perceptible outcomes. In order to get the students intrigued, this work aims to involve the students in building new solutions that perform the computer aided engineering functions. Many tools are available for the students to implement computer modeling and simulation that correctly solve sustainability problems and proposes metrics for references and progress tracking. This work suggests the Dot Net (.Net) environment with facilitated graphical user interfaces.

\section{Methodology}

In the beginning of this study, the students are asked to fill a survey that reflects their attitude toward following sustainability rules, and how far are they willing to contribute to upholding such rules, and finally, how do they feel about advocating it to their acquaintances. The survey was given, initially, to the students in the beginning of the semester without any introductions to sustainability; then, was given again in the end of the project with different phrasing seeking to 
obtain genuine and open answers. The two implemented survey questioners are appended in the end of this report (Appendix A). The preliminary stages introduced the students to the successful problem-solving methodology where the problems are identified and proper mitigation measures are defined. At this stage, the students are driven to perform initial research targeting their community to recognize the sustainability challenges faced by their own people in this day and age. Such interaction can be performed by media search or interacting with the public to identify the latest concerns and, hereafter, generate objectives and success criteria. This stage is crucial in the engineering design process but as crucial to the teachings of sustainability when students are involved to understand the impacts of sustainability negligence. The next step is for the students to identify functions that derives feasible actions to mitigate the waste of precious resources. Each objective requires at least one function to guarantee the solution success; besides, the identified functions help determining the possible methods and means to achieve the needed mitigations as illustrated in Figure 1. The determined methods are then used to derive correct mathematical models to enable simulation for further scaling and duplication. Effective research methodologies are implemented in this stage with the instructor's supervision making it an ideal setting to teach and train students the research methodologies with clear goals.

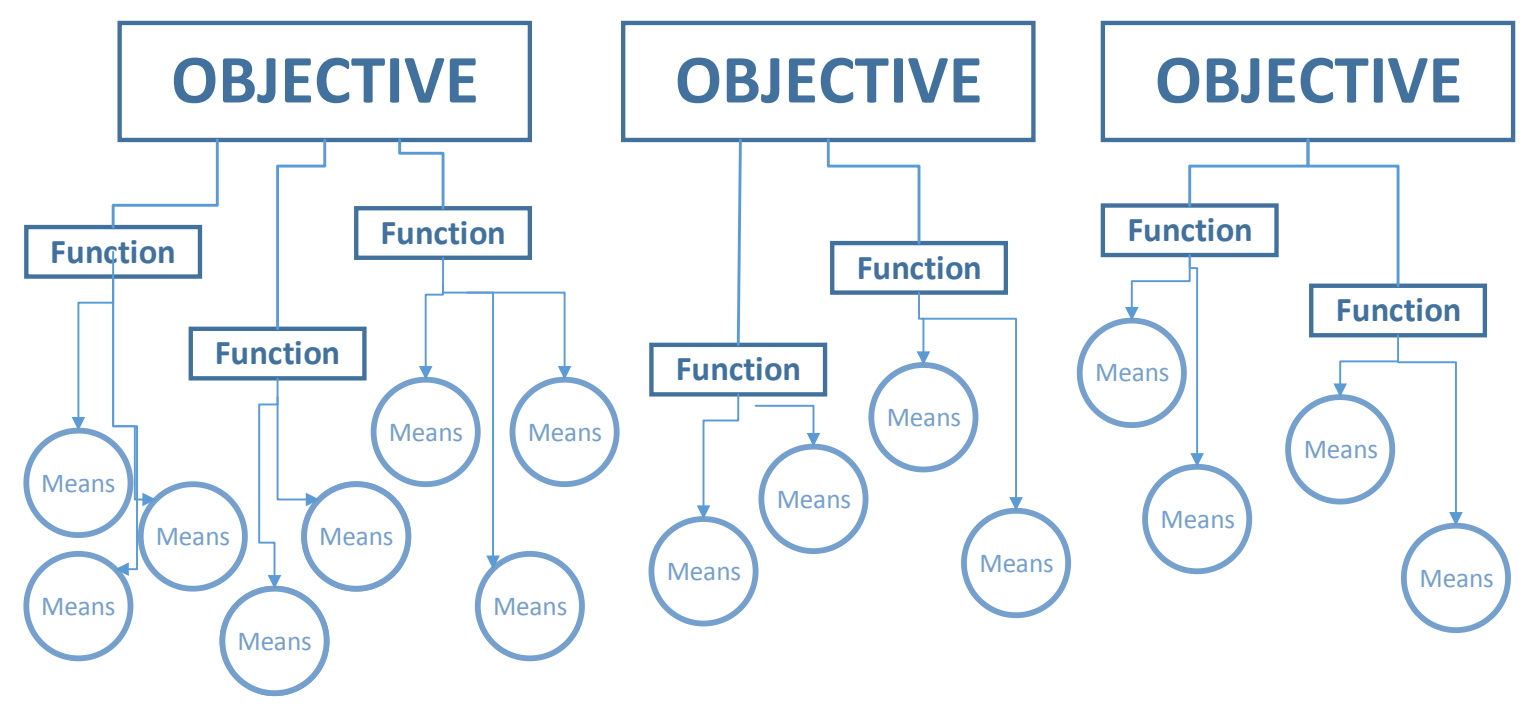

Figure 1: Problem definition stage; Objectives, Functions and Means.

Statistics is one of the predominant fields for sustainability research; hence, the student need to understand that the demeanor of individual can be significant when taken as population. Figure 2 shows that for a targeted region, the students are directed to find many useful census information such as the number of households, average size of households, number of vehicles for each household, size of dwelling areas, as well as, other related information such as lifestyles and common practices. According to an estimate by the World Bank, the UAE's population in 2018 stands at 9.543 million. The data collected is usually stored in database accessible by the system [11]. 


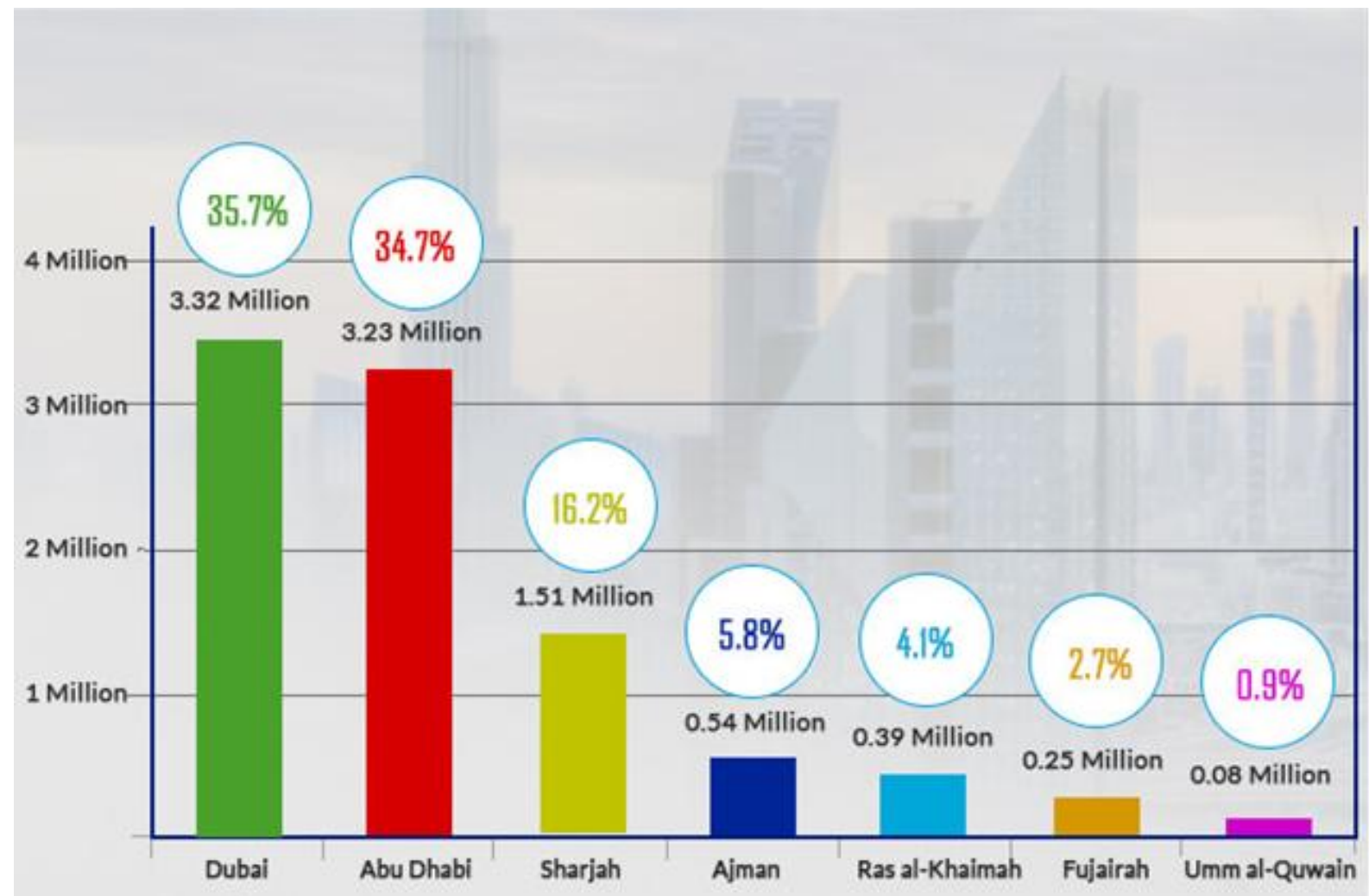

Figure 2: UAE population estimate 2018 [11]

Another track of research that the students are assigned to probe is the electricity consumption to enhance and appreciate the measures recommended by sustainability guidelines. As showing in Figure 3, a database is established to be integrated in the overall metrics for sustainability. In the same page, water consumption and water abuse research are undertook helping the students build another database for water sustainability measures. The students, also, need to be aware of the possible sustainability redemptions through waste management such as recycling which is the one practice that seems to be neglected and unappreciated by many for reasons that are pinned on the fact that the merit of recycling are inconspicuous [10]. One of the goals of this work is to open the student's eyes on the significance of the waste handling practices that does not only help increase the revenue of the community but it also reduce harmful effects to the environment. Transportation is one field that contribute significantly to the sustainability metrics; hence, the students are assigned with research tasks to probe the factors that contribute to the harmful consequences on the defined sustainable state. Identifying and understanding the causes of harm in the transportation field leads the students to conceptualize and search for proper mitigations that in turn will be augmented to the overall system. 
Electricity consumption per capita (kWh per person)

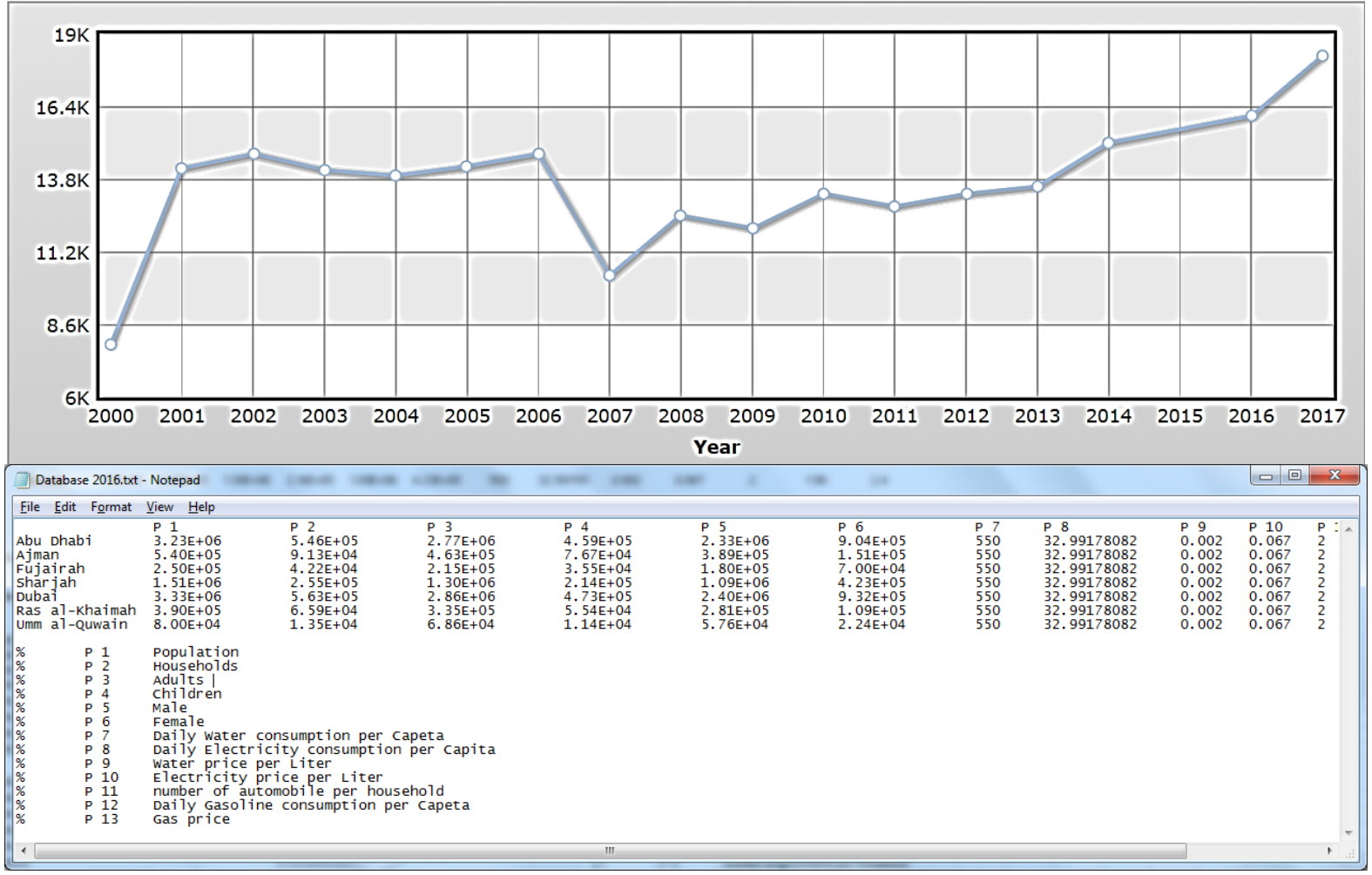

Figure 3: Example of statistics findings [11]

Up until this stage, the proposed study focuses on the students' ability to materialize the merits of sustainability especially when presented with monetary scope. However, to better appreciate the sustainability efforts, the students need to study the different pillars that define a sustainable world. It usually builds a shock to the students to learn that the endeavors to sustain the world does not stop at recycling and saving many.

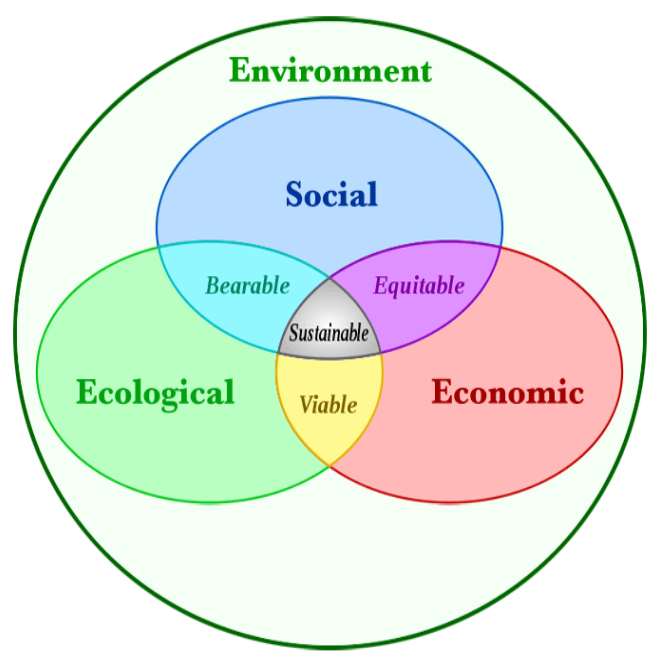

Figure 4: The three pillars of sustainability 
Showing in Figure 4, the students come to learn that sustainability is one of the leading arenas in maintaining human's stature, income and health, hence, it is important to understand the interrelated pillars to achieve such success [13]. The challenge, however, is finding metrics that models the proportional relations among the three pillars. Pye et al. [13] studied this relationship in an objective manner by examining the direct effects of environmental negligence on the social dimensions focused on the European regions to analyze the linkages between the environmental and social strategies. As sought, such studies propose solutions optimize the potential synergies among the environmental, social and economic sustainability measures [13]. Some of the studies recommend Artificial Intelligent (AI) tools to propose correct ways to model the intercut aspects of sustainability. Such works expose the students to the cutting-edge technologies that help them create objective reasoning for subjective decisions. A study by Khoshnava et al. [14] applies a hybrid decision making methodology to resolve multiple incompatible and conflicting criteria to align the three pillars of sustainability with a particular objective. As illustrated in Figure 5, the proposed solution is a hybrid model that employs fuzzy analytic network process for aligning and ranking sustainability criteria based on the social, environmental and economic aspect of sustainability [14].

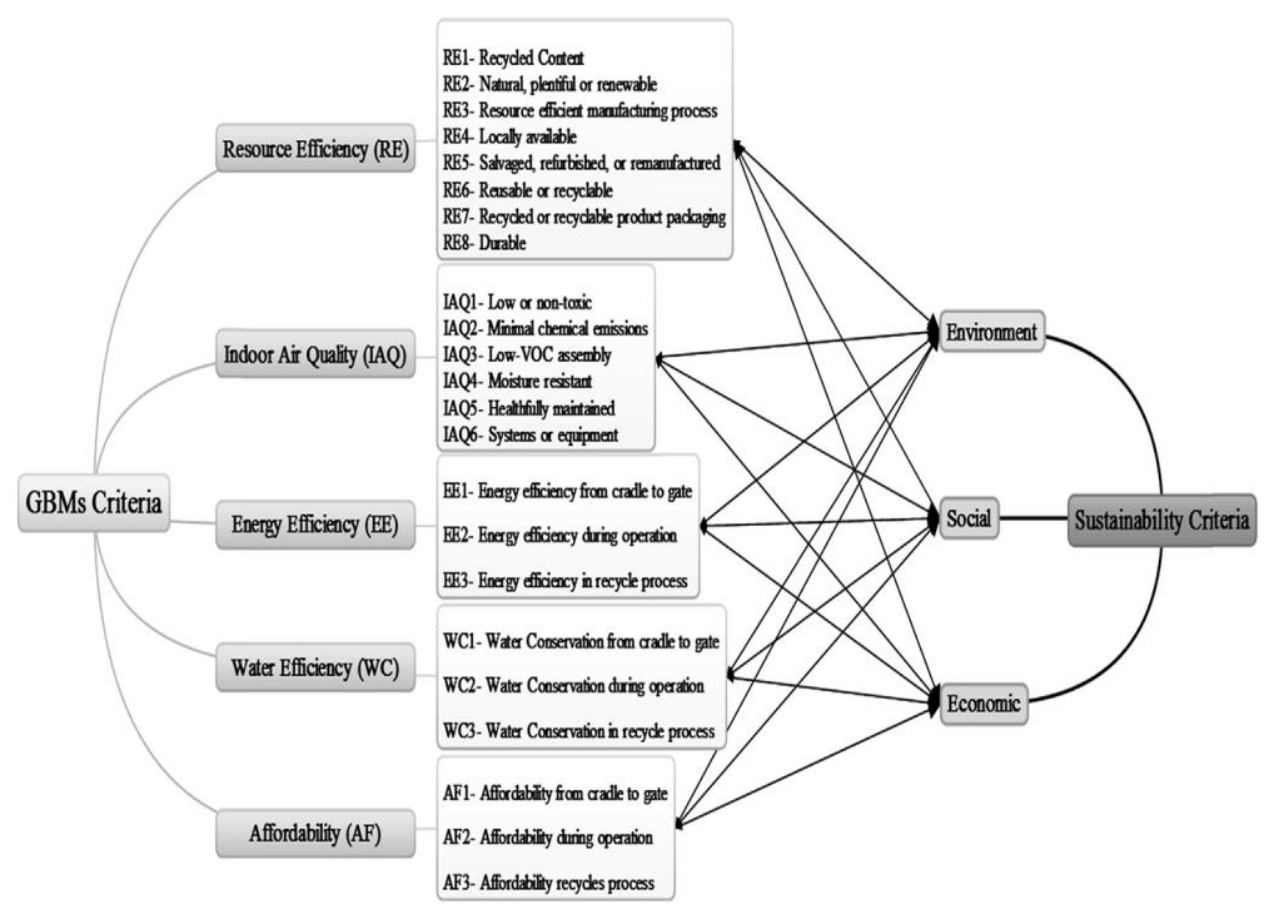

Figure 5: AI provide suitable tools to align the three pillars of suitability

\section{Computer Aided Engineering Modeling}

One of the proposed tools used to expose the students to the CAE is SolidWorks which is equipped with tools and features that allows the user to design, model and simulate parts and products. Nonetheless, SolidWorks also helps the students with many sustainability measures 
that lead to the proper selection of the materials that make the designed product durable and safe to the environment during manufacturing, utilization and at the end of its lifecycle. In order to show the impacts of recyclability, SolidWorks was used to expose the impact of the multiple hot items with attributes such as high volume demands, reusable, recyclable and scarce. Each item is modeled through CAD with proper materials and dimensions then are evaluated based on the region of production, manufacturing processes, duration of use, and cost. The students perform multiple attributes manipulations and compare the findings with different recycling measures. The figure below shows the outcomes with the percentage of sustainability improvement between recycled water bottles and non-recycled ones.

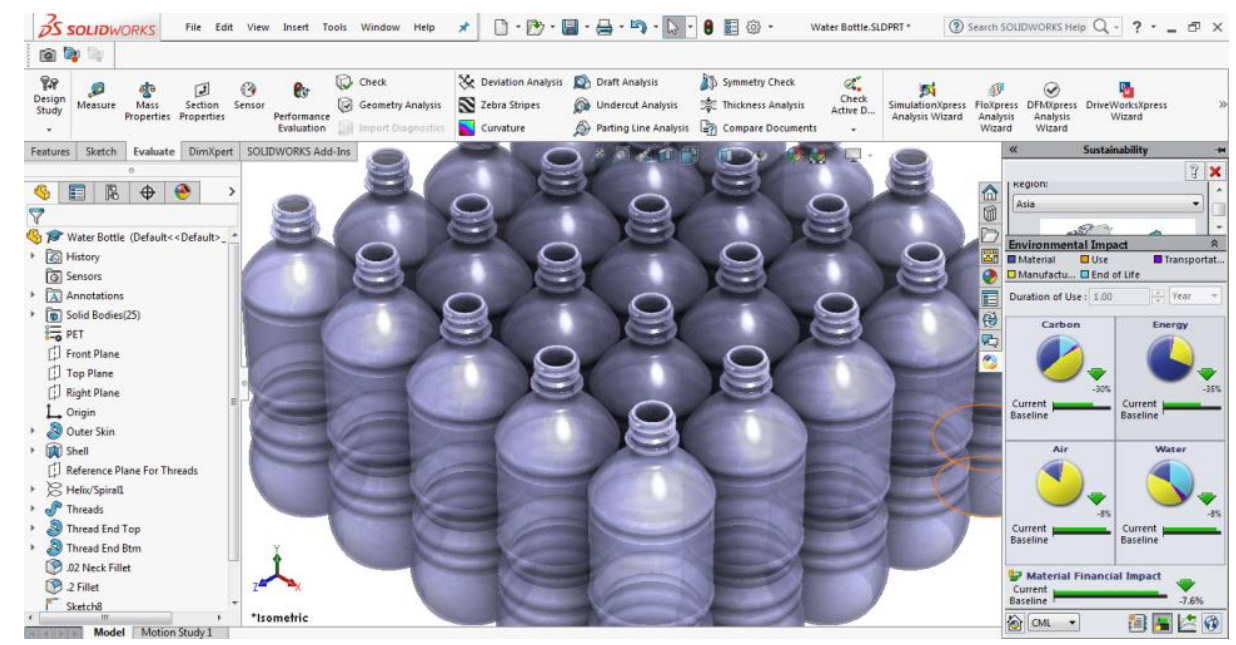

Figure 6: CAE for Sustainability

SolidWorks and many CAD programs seem to interest the students, but fails to contribute to the impacts of the social and other sustainability factors. Hence, this study suggest the use of multiparadigm numerical computing environment. The students here are assigned with creating mathematical models that are logical and can output four types of values; one is monetary value and three values that represent improvement on the environmental, economic and social impacts. For example, the study tests the national impacts if each household in the region decides to start recycling water bottles.

$$
R E 1=p p p \times n p h \times h n \times \mathrm{hn} \times T
$$

Where ppp is the price saved per piece recycled, $\mathrm{nph}$ is the estimated number of pieces used per household in a day, $\mathrm{h}$ is the number of households in the region, $\mathrm{hn}$ is the average number of individuals in a household and $\mathrm{T}$ is time in days.

In the multi-paradigm numerical computing tool, the student populate the databases that capture all the needed parameters for all the mathematical models. The tool allows for fast and complex combination of models to build multiple scenarios and observe the impact of change on the fly. Seeking to expedite such outcomes, the study employs graphical user interfacing (GUI) that makes the process easy and effective. 


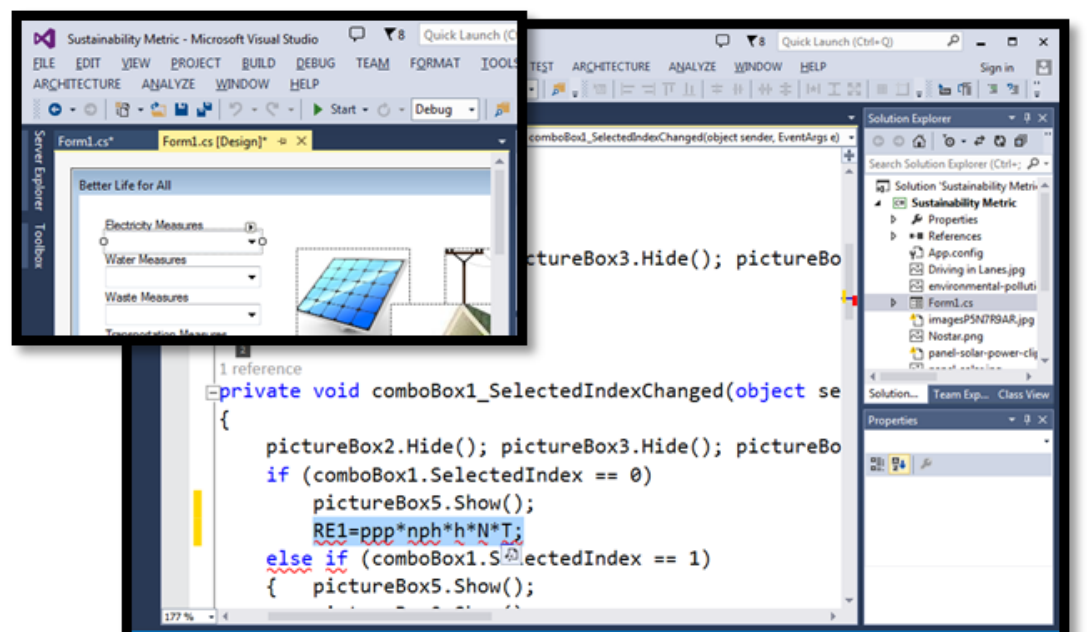

Figure 7: .Net software allows for multiple attribute modeling for fast output testing

The next phase is exposing the students to the three pillars of sustainability and the innovative approaches to quantify the environmental, social and economic merits of sustainability. Initially, the students study the latest research on methods to calculate the impact of people's devotion and negligence on the three pillars. The students then build three templates that represents best, medium and worst case scenarios (5, 3 and 1 Stars respectively). These templates are aligned with the correct parameter that proved to produce the designated rating. Next, the students are introduced to an artificial intelligence capability that performs decision-making to generate a value $(1-5)$ that represents the level of improvement on sustainability. As showing in Figure 8 , Neural Network tools supported by MATLAB was used to allow the student to carryout AI methods to quantify all aspects of sustainability including Environment impact, social impact and economic impact by training the network with the predefined templates.

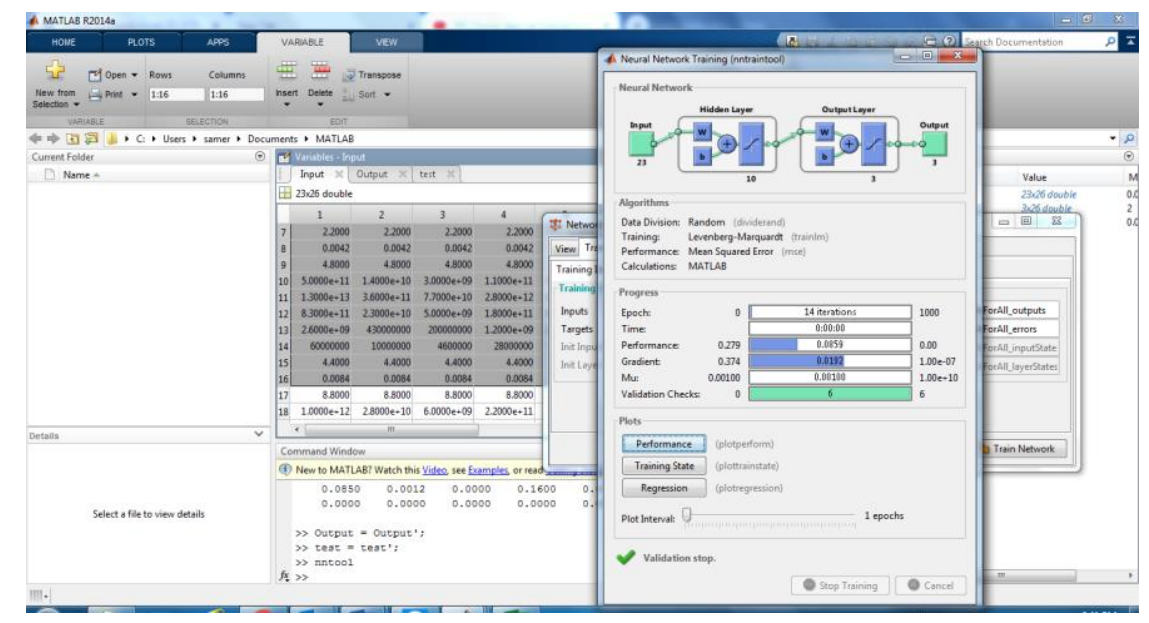

Figure 8: Neural Network tool allows for easy and fast rating of the sustainability lifestyle based on trained scenarios

Dot Net (.Net) framework by Microsoft provides another tool that opens the venue for more modeling capabilities to the students. Being object oriented, .Net provides a class library that 
provides graphical user interface based on familiar Windows layout that can be controlled by familiar controllers such as buttons, pull-down list, pictures, tabs and more. The program is equipped with database capabilities to store and retrieve statistical information and can be presented in an easy to share format. Moreover, database connectivity is permitted for information flow and concurrent collaboration. However, for swift execution, cryptography is endorsed to simplify complex algorithms into names that call for locked dynamic classes allowing extensibility of the .Net framework cryptography classes. The students are also equipped with web application development, numeric algorithms, and network communications [15]. The proposed work also suggests using preset templates that are simplified and resilient for the students to allow for alteration. Figure 9 shows a seed .Net GUI in which the students are given with guidelines to hypothesize scenarios and build proper solutions.

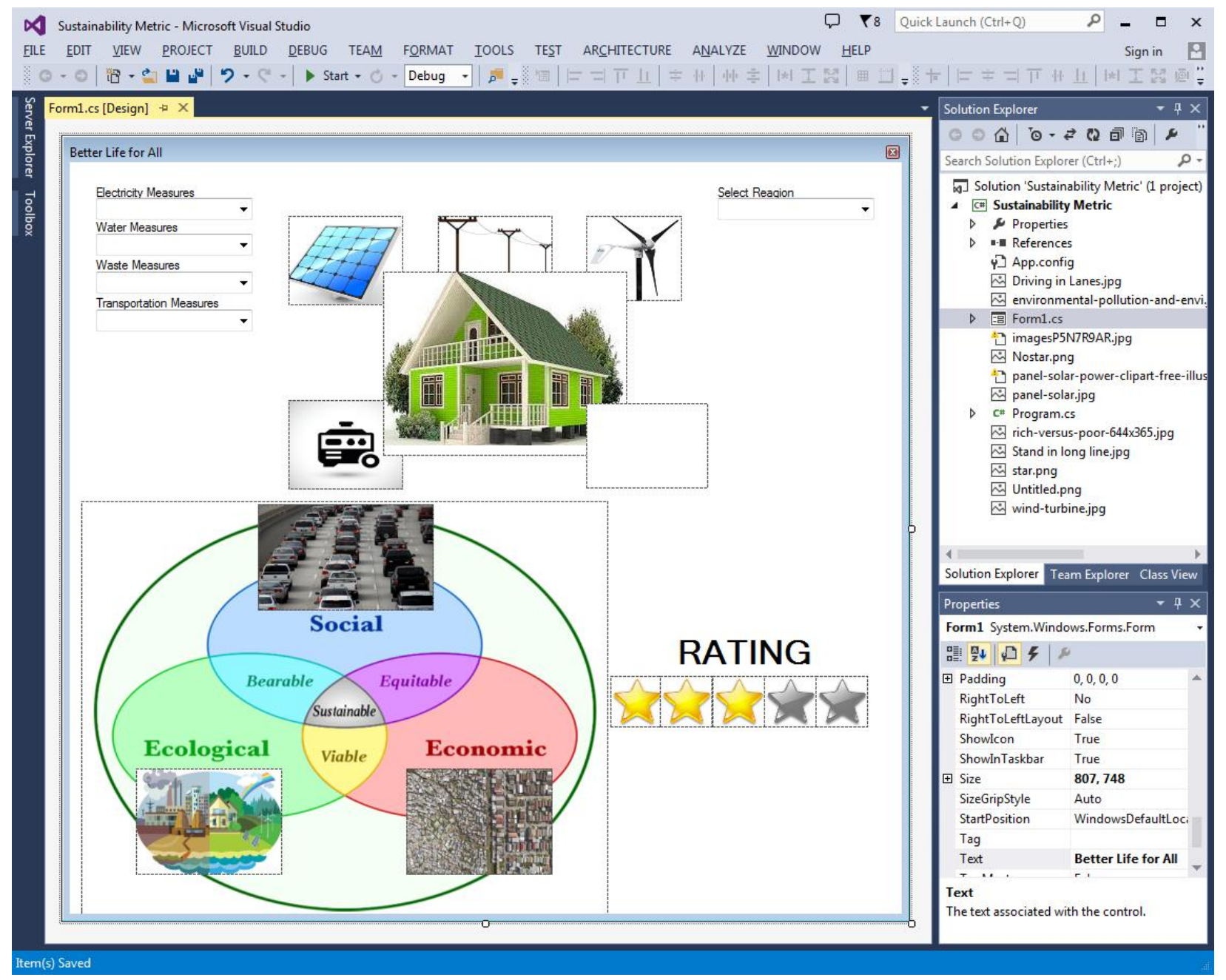

Figure 9: Snapshot of a predefined .Net GUI

Behind the scenes, the proposed sustainability program is student friendly and can be coped with few tutorials. The students are taught to perform mathematical modeling for the searched mitigations such as the amount of resource savings with specific sustainable measures. The students are also guided to manage the needed information by populating the data in libraries to 
be summoned when needed; similarly, they learn how to create proper reports that reflect their findings for sharing and communication. Down the road, the students are delegated with constructing correct models that govern the interrelating factors among the environmental, social and economic effects and circumvent possible risks that may jeopardize the success of the system. Such work can be simple and straightforward by using proportional relationships or can be sophisticated by implementing artificial intelligence. The level of sophistication depends on the students' classifications and aptitudes but is open for the students to excel.

\section{Results and Observations}

The proposed system was implemented on freshmen engineering students to observe and assess the outcomes. The study targeted a group consisted of 21 mixed-gender students in an Introduction to Engineering Design class. The students were assigned to work in teams to apply engineering design methodology and find solutions that overcome many sustainability challenges within their community. The study started by having the students answer a questionnaire that reflects their level of understanding of sustainability and their determination to be involved in sustainability upholding efforts. As expected, many of the students were challenged when asked to connect sustainability with the social and economic outcomes, hence, many were reluctant to go the extra mile and get involved in sustainability practices, let alone endorse them to friends and family.

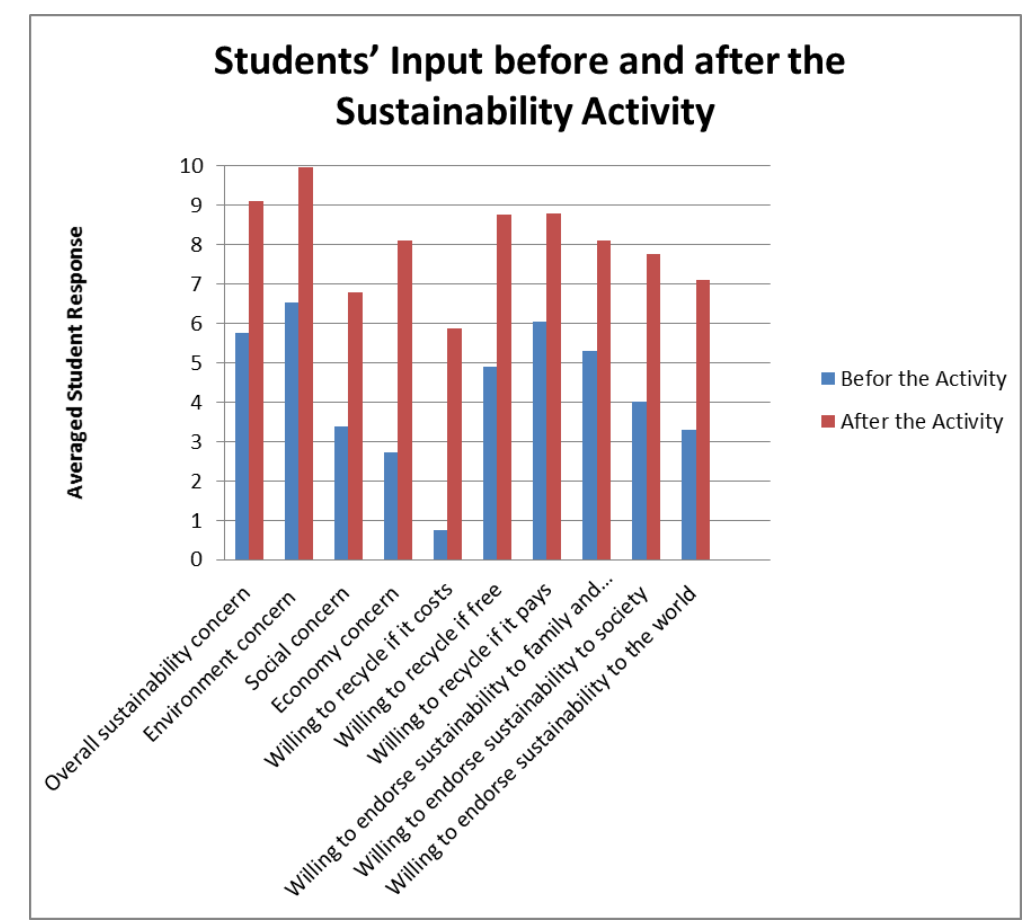

Figure 10: Students' reflections on sustainability changed after carrying out the activity which drove them to understand sustainability and appreciate its consequences.

Showing in Figure 7, the student's appreciation for sustainability has improved in multiple dimensions that include environment, social and economic. Also showing, the students become more willing to adopt good sustainability practices with and without conspicuous incentives. 
Observed from the outcomes of one activity that took one month's efforts showed close to $38 \%$ overall improvement of the student attitude towards sustainability appreciation. Hence, educators of engineering and other professions should consider a curricular structure that endorses such teachings to guarantee generations of advocates for sustainability.

\section{CONCLUSION}

Application based education showed better outcomes when exposing the students to new tools and methodologies and in light of this, Computer Aided Engineering proved to facilitate education application by simulating solution to represent real living scenarios with speed and convenience. This work proposes employing Computer Aided Engineering approaches to help the engineering students gain better understanding of sustainability and its magnitudes that reflect on their society's needs. The work suggests that one of the best means to learn and trust in sustainability is to apply solutions to the problems faced by their own society. In order to have the students believe in sustainability impacts, they are assigned to perform research to uncover the association of sustainability on the environment, society and economy. Environment research oversees the likelihood that mother earth will still be a safe haven for them and for the upcoming generation. Nonetheless, the environment is not the only aspect of sustainability to be appreciated in this work, the students also, come to realize that sustainability play major roles in enhancing the social ties and individuals' social standings. Additionally, the students learn about many economic advantages linked to the people adherence to sustainability guidance. One of the best methods to tackle such multi-dimensional problem is by using multi-paradigm numerical computing tools that allow for numerical analyses, database capabilities and modeling. Students' reflections are recorded before and after the implementation of the proposed methodology. The results show that the students' prospective on sustainability has improved with more consideration and care. This work is recommended for further investigation to track the progress of the students as they mature through their engineering education and radical augmentations should be considered in the engineering education curricula to build leaders who are willing to take the responsibility of upholding and improving all the suitability guidelines.

\section{REFERENCES}

[1]. C. Graham, "Subjective Well-Being in Economics," Oxford Handbooks Online, 2016.

[2]. S. Woodcraft, T. Hackett, and L. Caistor-Arendar, Design for social sustainability: a framework for creating thriving new communities. London: Young Foundation, 2011.

[3]. A. D. Basiago, The Environmentalist, vol. 19, no. 2, pp. 145-161, 1998.

[4]. R. Brinkmann, Introduction to Sustainability. Chinchester: Wiley-Blackwell, 2016.

[5]. J. C. Dernbach and J. A. Mintz, "Environmental Laws and Sustainability: An Introduction," Sustainability, vol. 3, no. 3, pp. 531-540, 2011. 
[6]. A. Lang, "Business and Sustainability: A Synopsis," Business and Sustainability Sustainability and Innovation, pp. 179-192, 2014.

[7]. C. Gauthier and T. Daudigeos, "Sustainability Education: Crossing Theory and Practices," The International Journal of Sustainability Education, vol. 11, no. 2, pp. 27-33, 2015.

[8]. L. L. Grange, "Environmental Education after Sustainability," Post-Sustainability and Environmental Education, pp. 93-107, 2017.

[9]. N. Seyajah, "An Investigation on Sustainable Design Index and its Implementation within the CAD Environment," Cad15, 2015.

[10]. A. Ittiravivongs, "Recycling as Habitual Behavior: The Impact of Habit on Household Waste Recycling Behavior in Thailand," Asian Social Science, vol. 8, no. 6, 2012.

[11]. "World Bank Open Data," Literacy rate, adult female (\% of females ages 15 and above) | Data. [Online]. Available: https://data.worldbank.org/. [Accessed: 04-Feb-2019].

[12]. K. Anderson, "Social Policy Dimensions of Economic Integration: Environmental and Labour Standards," 1996.

[13]. S.T. Pye, I Skinner, N Meyer-Ohlendorf, A Leipprand, K Lucas, R Salmons, “Addressing the social dimensions of environmental policy - A study on the linkages between environmental and social sustainability in Europe". Report commissioned by European Commission, DG for Employment, Social Affairs and Equal Opportunities 2008.

[14]. S. M. Khoshnava, R. Rostami, A. Valipour, M. Ismail, and A. R. Rahmat, "Rank of green building material criteria based on the three pillars of sustainability using the hybrid multi criteria decision making method," Journal of Cleaner Production, vol. 173, pp. 82-99, 2018.

[15]. Schildt, H. (2009). C\# 3.0: the complete reference. New York: McGraw-Hill Companies. 


\section{APPENDEX A}

Sample of Student's Initial Surveys

\section{STEP 201 (Strategies for Team-based Engineering Problem Solving) Sustainability Survey I}

Please circle the number below that indicates how much you agree or disagree with each statement. Circle one number for each statement.

\begin{tabular}{|c|c|c|c|c|c|c|c|c|}
\hline 1 & \multicolumn{8}{|c|}{ How much do you contribute to sustainability? } \\
\hline 1 & \begin{tabular}{l|l|l} 
& 2 & 3 \\
\end{tabular} & 4 & 5 & 6 & 7 & 8 & 9 & 10 \\
\hline
\end{tabular}

\begin{tabular}{|l|l|l|l|l|l|l|l|l|l|}
\hline $\mathbf{2}$ & \multicolumn{7}{|c|}{ How much does UAE contribute to global warming problems? } \\
\hline 1 & 2 & 3 & 4 & 5 & 6 & 7 & 8 & 9 & 10 \\
\hline Not at all contributing & Neutral & \multicolumn{5}{c|}{ Highly contributing }
\end{tabular}

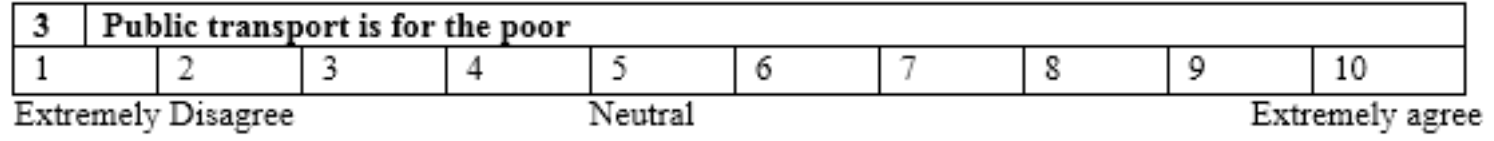

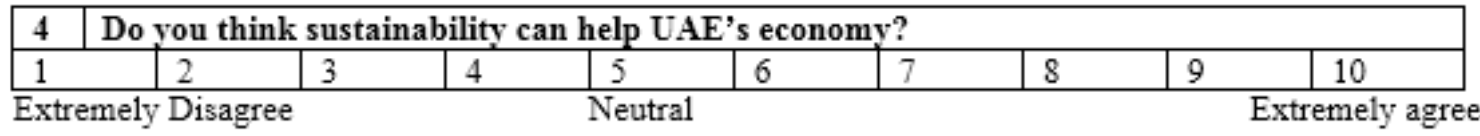

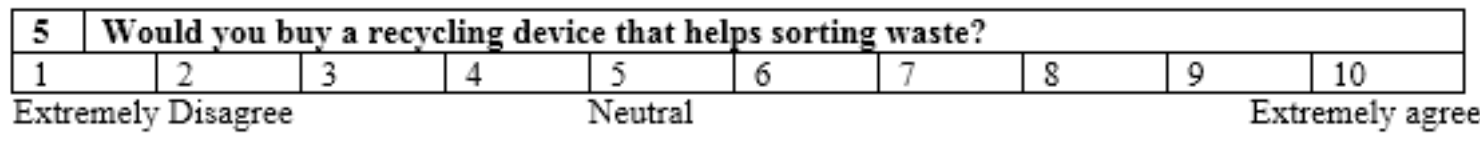

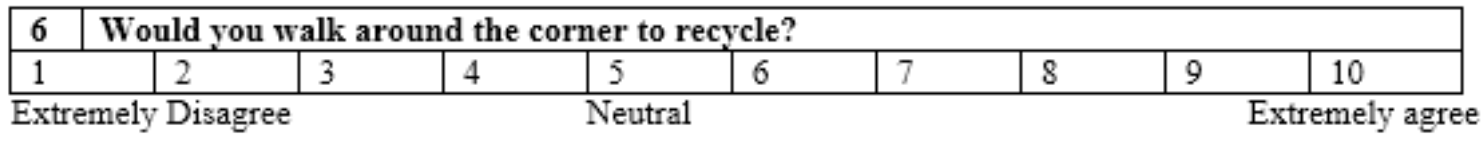

\begin{tabular}{|c|c|c|c|c|c|c|c|c|}
\hline 7 & \multicolumn{8}{|c|}{ Would you recycle if you can save on weekly basis? } \\
\hline 1 & \begin{tabular}{l|l} 
& 2 \\
\end{tabular} & 3 & 4 & 5 & 6 & 8 & 9 & 10 \\
\hline
\end{tabular}

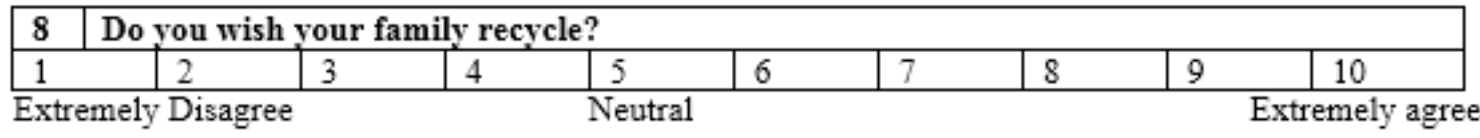

\begin{tabular}{|c|c|c|c|c|c|c|c|c|c|}
\hline 9 & \multicolumn{9}{|c|}{ Would you participate in the UAE Green Festival? } \\
\hline 1 & & 3 & 4 & 5 & 6 & 7 & 8 & 9 & 10 \\
\hline
\end{tabular}

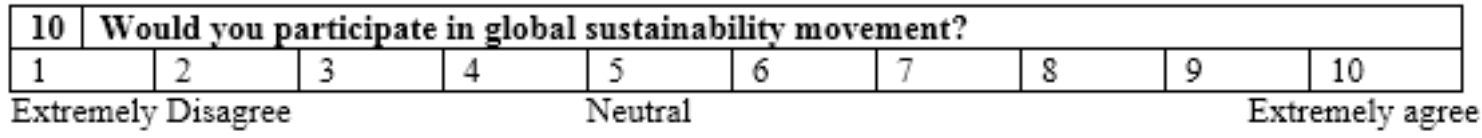




\section{APPENDEX B}

Sample of Student's Final Surveys

\section{STEP 201 (Strategies for Team-based Engineering Problem Solving) Sustainability Survey II}

Please circle the number below that indicates how much you agree or disagree with each statement. Circle one number for each statement.

\begin{tabular}{|l|l|l|l|l|l|l|l|l|l|}
\hline $\mathbf{l}$ & \multicolumn{7}{|c|}{ How much are you concerned about the environment? } \\
\hline 1 & 2 & 3 & 4 & 5 & 6 & 7 & 8 & 9 & 10 \\
\hline
\end{tabular}

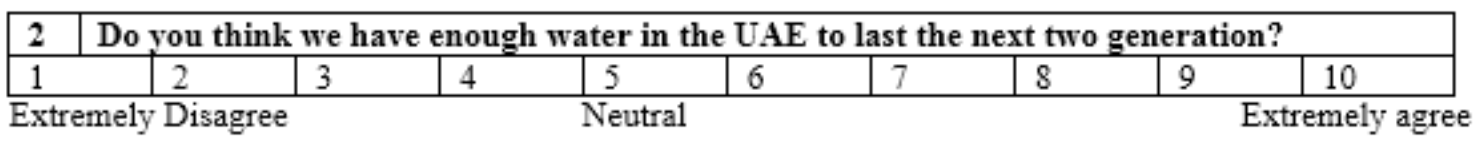

\begin{tabular}{|c|c|c|c|c|c|c|c|c|c|}
\hline 3 & \multicolumn{9}{|c|}{ Would you ride the bus if it means better place for your great grandchildren? } \\
\hline 1 & \begin{tabular}{l|l} 
& 2
\end{tabular} & \begin{tabular}{|l|l|}
2 & 3
\end{tabular} & \begin{tabular}{l|l|} 
& 4
\end{tabular} & \begin{tabular}{|l|l|} 
& 5 \\
\end{tabular} & 6 & 7 & 8 & 9 & 10 \\
\hline
\end{tabular}

\begin{tabular}{|l|l|l}
4 & Every drop of water we save put money in the nations treasure
\end{tabular}

\begin{tabular}{|l|l|l|l|l|l|l|l|l|l|}
\hline 1 & 2 & 3 & 4 & 5 & 6 & 7 & 8 & 9 & 10 \\
\hline
\end{tabular}

$\begin{array}{llll}\text { Extremely Disagree } & \text { Neutral } & \text { Extremely agree }\end{array}$

\begin{tabular}{|c|c|c|c|c|c|c|c|c|c|}
\hline 5 & \multicolumn{9}{|c|}{ Would you donate for a recycling plant in UAE? } \\
\hline 1 & \begin{tabular}{l|l} 
& 2 \\
\end{tabular} & 3 & \begin{tabular}{l|l|} 
& 4 \\
\end{tabular} & \begin{tabular}{|l|l|} 
& 5 \\
\end{tabular} & 6 & 7 & 8 & 9 & 10 \\
\hline
\end{tabular}

\begin{tabular}{|l|l}
\hline 6 & Would you walk around the corner to recycle?
\end{tabular}

\begin{tabular}{|l|l|l|l|l|l|l|l|l|l|}
\hline 1 & 2 & 3 & 4 & 5 & 6 & 7 & 8 & 9 & 10 \\
\hline \multicolumn{7}{|c|}{ Neutral } \\
Extremely Disagree
\end{tabular}

\begin{tabular}{|l|l|l|l|l|l|l|l|l|l|}
\hline 7 & If recycling returns annual income. Would you recycle everything? \\
\hline 1 & 2 & 3 & 4 & 5 & 6 & 7 & 8 & 9 & 10 \\
\hline
\end{tabular}

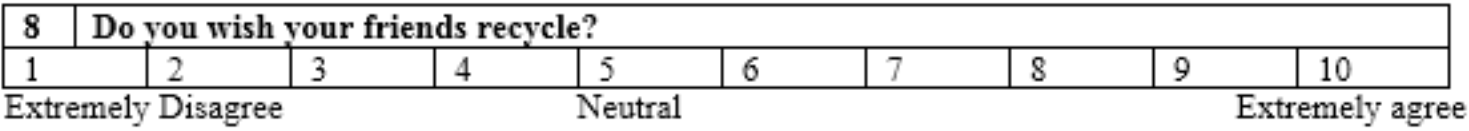

\begin{tabular}{|c|c|c|c|c|c|c|c|c|}
\hline 9 & \multicolumn{8}{|c|}{ Would you start a sustainability club in UAE? } \\
\hline 1 & \begin{tabular}{l|l|l} 
& 2 & 3 \\
\end{tabular} & \begin{tabular}{l|l} 
& 4 \\
\end{tabular} & \begin{tabular}{|l|l|} 
& 5 \\
\end{tabular} & 6 & 7 & 8 & 9 & 10 \\
\hline
\end{tabular}

\begin{tabular}{|l|l}
\hline 10 & Do you want the whole world follow sustainability?
\end{tabular}

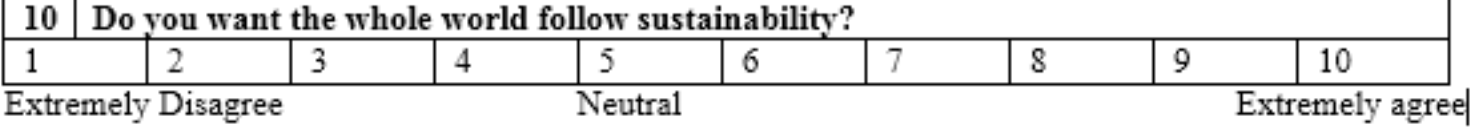

